\title{
ПОСТРОЕНИЕ ТИПОВОЙ МОДЕЛИ КЛАСТЕРА КАК ОСНОВНОГО ИНСТРУМЕНТА ИССЛЕДОВАНИЯ ПРОСТРАНСТВЕННОЙ КЛАСТЕРИЗАЦИИ В ОТРАСЛИ СТАНКОСТРОЕНИЯ
}

\author{
(c) 2019 Морозова Екатерина Владимировна \\ директор по развитию \\ ООО «Производственная компания «Корстэл» \\ 398007, г. Липецк, пл. Заводская, 1 \\ E-mail: evmorozova26@mail.ru
}

В статье рассмотрена теоретическая модель станкостроительного кластера как инструмент исследования пространственной кластеризации региональной экономики. Обосновывается идея единой методической основы по созданию промышленных кластеров, обеспечивающих стабильный экономический рост в отрасли станкостроения.

Ключевые слова: промышленный кластер, кластерная политика, станкостроение, модель кластера, исследование пространственной кластеризации.

На сегодняшний день теория развития пространственных кластеров в экономике активно развивается. В ряде исследований разработаны практические подходы к применению теории кластеров в различных отраслях как российской экономики, так и за рубежной. В рамках данной статьи интерес представляют исключительно пространственные кластеры.

Широкое применение теории пространственной кластеризации послужило началом исследований и разработок большого числа методик для обоснований этого процесса. Одним из самых распространенных и научно принятых на сегодняшний день можно считать определение кластера, данное М. Портером, который это понятие и ввел. Кластер понимается как группа географически соседствующих взаимосвязанных компаний и связанных с ними организаций, действующих в определенной сфере, характеризующихся общностью деятельности и взаимодополняющих друг друга [1]. В каждом пространственном кластере, как и в таком, где пространство как фактор несущественно, существует основная производственная деятельность, которая получила название «якорной».

В развитии регионов, где соблюсти один из главных критериев успеха кластеризации - географическую близость участников,представляется наиболее возможным, в государстве возникает потребность в поддержании приоритетных направлений, связанных с ключевыми отраслями экономики (космические программы, атомная промышленность, энерге- тика, машиностроение, самолетостроение, оборонный заказ и т.д.), именно на уровне региональных кластеров.

Говоря об отечественно экономике, можно сказать, что машиностроение является базовой отраслью нашей страны. Станкостроение как один из видов машиностроения создает для всех промышленных отраслей металлообрабатывающие станки и центры, кузнечно-прессовое оборудование, многофункциональные агрегаты для обработки дерева, пластика, композитов и других материалов. Станкостроение является зеркалом развития машиностроения, и по развитию этой отрасли во многом можно судить о развитии промышленного потенциала всей страны. Иными словами, станкостроительная промышленность - это одна из фондообразующих отраслей машиностроения, которая обеспечивает любое производственное предприятие машинами и оборудованием, а конечного потребителя - необходимыми предметами потребления. Модернизация отечественных производств, благодаря развитию отрасли станкостроения, позволит повысить конкурентоспособность готовой продукции, увеличить производительность, снизить как материальные, так и трудовые издержки.

Выведенная «формула» экономического успеха дает понимание необходимости всестороннего развития и поддержки данной отрасли. В данном случае применение к предприятиям станкостроительной отрасли кластерного подхода с получением в будущем так необходимого 
синергетического эффекта от совместной деятельности участников кооперации в кластере отвечает условиям быстрого развития данной отрасли [2]. Насколько эффективно будет организовано взаимодействие всех участников станкостроительного кластера, настолько и больших эффектов возможно будет достичь для региональной и федеральной экономики.

Развитие кластеров в отрасли станкостроения не ново для нашей страны. Тем не менее, при достаточном количестве исследований аналитического характера нет единства мнений по теоретической модели такого кластерного образования. В работах исследователей встречается различное обоснование кластерной теории и схематичное изображение структуры кластера. Рисунки с изображением кластерных коопераций участников таких объединений настолько разнообразны, что очень сложно объединить их в определенные группировки для обобщения и выработки рекомендаций по практическим расчетам эффективности и построению модельно работающей кластерной структуры. Факт множественности подходов к кластерному анализу делает сложным выработку конкретных мер по развитию кластеров в различных отраслях экономики со стороны региональных и федеральных органов власти, проводящих государствен- ную промышленную политику.

Разработка единого методологического подхода к модели пространственного кластера в отрасли станкостроения требует применения общенаучных методов исследования, прежде всего, системного анализа. Системный анализ рассматривает каждый объект как систему с совокупностью структурных элементов внутри [3]. Система также является элементом, взаимодействующим в более глобальной системе.

Основным элементом взаимосвязи в кластере выступают кооперационные связи между его участниками [4]. Таким образом, при построении типовой модели кластера станкостроения, можно использовать в качестве теоретической основы модель системного анализа - «Черный ящик» (рисунок 1).

Применение данной модели при описании процессов, происходящих в кластере, возможно при использовании понятий системного подхода, где «входом» будут являться предприятия малого и среднего предпринимательства, являющиеся поставщиками сырья, материалов и комплектующих для якорных производителей, «выходом» в данной модели станут покупатели готовой продукции кластера (рисунок 2).

Принимая во внимание основную цель построения типовой модели пространственного

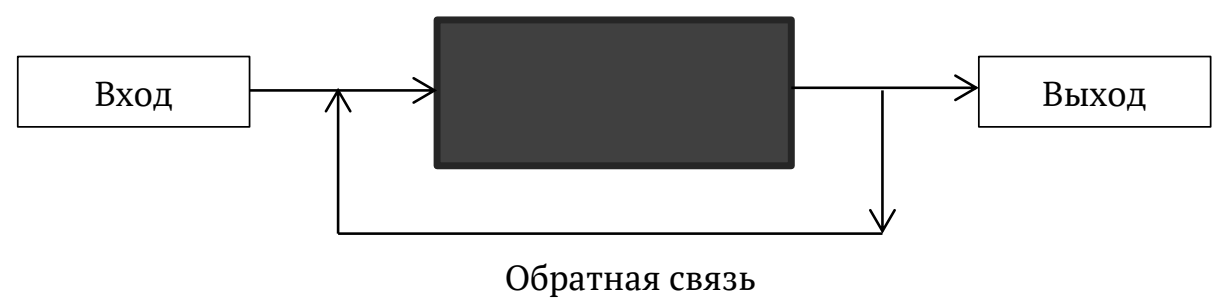

Рис.1. Модель «Черный ящик»: системный анализ

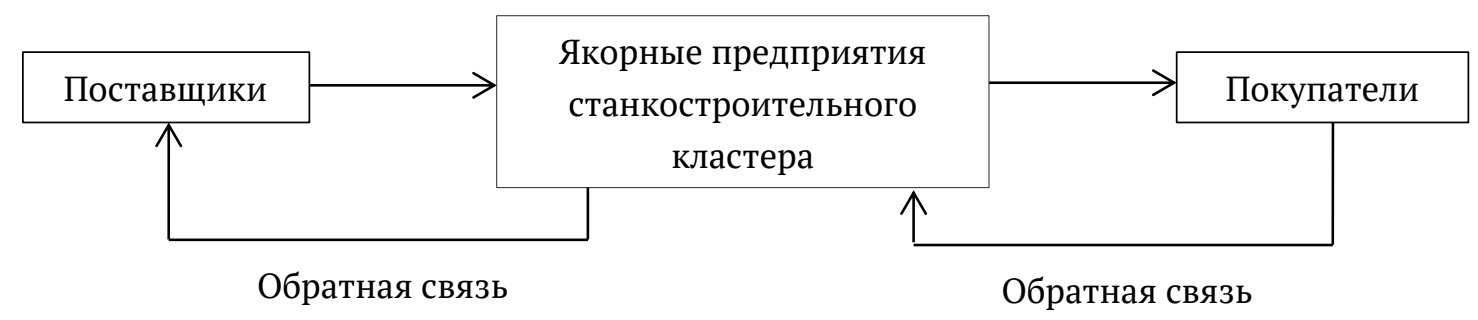

Рис.2. Адаптация модели «Черный ящик» к описанию экономических процессов в кластере 
кластера в отрасли станкостроения - анализ конкурентоспособности, применим модель М. Портера «Силы, управляющие конкуренцией в отрасли» [1] и определим основные элементы взаимодействия.

Исследуя природу станкостроительной отрасли, можно сделать вывод, что основными элементами станкостроительного кластера, образующими пространственную кластеризацию, можно считать:

- якорные станкостроительные предприятия (совокупный объем производства, численность высокопроизводительных рабочих мест, объем налоговых отчислений);

- внутренние и внешние поставщики (предприятия малого и среднего бизнеса, поставляющие сырье и материалы, комплектующие; поставщики электроэнергии, газа, воды);

- внутренние и внешние потребители (покупатели продукции в кластере, экспорт);

- научная и образовательная инфраструктура (исследовательские институты, ВУЗы, ССУЗы, техникумы и колледжи машиностроительной и технической направленности);

- инфраструктура поддержки (инновационная и технологическая инфраструктура, технопарки, центры коллективного пользования, логистические услуги, консалтинг);

- кредитные ресурсы (микро-кредитные и кредитные организации, банки, региональный и федеральный Фонд развития промышленности);

- административная поддержка (региональные управления / департаменты / министерства по развитию промышленности, Минпромторг России).

В соответствии с моделью «Черный ящик» все системные элементы структурированы в типовую модель станкостроительного кластера, которая будет состоять из четырех модулей:

1. Ядро (якорный бизнес).

2. Поставщики ядра.

3. Потребители конечной продукции.

4. Инфраструктура поддержки.

Детально анализируя каждый выделенный модуль в структуре типовой модели станкостроительного кластера, можно дальнейшее построение логической цепочки научных исследований представить следующими модулями.

Модуль 1: Все промышленные участники кластера сгруппированы по видам конечной продукции и производственным переделам.
Здесь же дается оценка вклада предприятий в экономику региона и развитие отрасли в целом.

Модуль 2: Анализируются поставщики якорных предприятий кластера. Здесь будет уместна классификация на внутренних и внешних поставщиков, в том числе и поставщиков из других регионов. Оценка влияния иногородних поставщиков кластера дает понимание о возможностях «наращивания» кластера и локализации производства ввозимых товаров для нужд якорных участников. Поставщики также группируются по видам поставок.

Модуль 3: Потребители конечной продукции станкостроительного кластера, разделенные на группы: «внутреннее потребление», «межрегиональные поставки», «экспорт». Данное разделение представляет собой существенную новизну в анализе потребителей, так как дает возможность оценить экспортные поставки как основной критерий эффективности пространственного кластера и разработать меры государственной поддержки кластера, исходя из возможности наращивания экспортных поставок станкоинструментальной продукции.

Модуль 4: Инфраструктура поддержки. В данный блок включаются все непроизводственные участники кластера, способствующие его всестороннему развитию, в том числе реализации кластерных инициатив и проектов: научная и образовательная инфраструктура, инновационная и технологическая инфраструктура, кредитные организации, административная поддержка.

Важно отметить теоретические особенности типовой модели станкостроительного кластера. В соответствии с взятым за основу понятием «кластер» М. Портера, придерживаемся теории пространственной кластеризации и географической близости всех участников кластерного объединения. Тем не менее, в предлагаемую типовую модель станкостроительного кластера, включены внешние поставщики и производители, то есть предприятия, не входящие в данный региональный кластер. Данная теоретическая особенность имеет важное значение для развития кластерной промышленной политики.

Во-первых, возможность локализации производств на территории кластера, при замене внешнего поставщика на внутреннего путем реализации инвестиционных проектов и кластерных инициатив; целесообразность перехода на местные сырье и услуги: разработка мер по 
региональной административной поддержке.

Во-вторых, целесообразность размещения всех переделов при производстве конечной продукции станкостроительного кластера на его территории, начиная от сырья и заканчивая системами числового-программного управления, создания дополнительной цепочки добавленной стоимости.

B-третьих, пространственные кластеры потому и характеризуются такой определенностью вида, что в существенной мере «встроены» в пространство своей дислокации, черпая из своей дислокации новые возможности, предоставляемые территориальной инфраструктурой, особенностями пространственной конфигурации производств, возможностями экономико-географического положения, новой ролью региональных органов управления по использованию территориальных производительных сил: словом - тем, что в литературе получило название субъектизации городов и регионов, в том числе при формировании пространственных кластеров [5, с.211-212].

Таким образом, включение в типовую мо- дель станкостроительного кластера элементов «внешние поставщики» и «внешние покупатели», территориально локализованных на той же «площадке», и которые теоретически в кластер не входят, позволяет проводить важнейший экономический анализ по обоснованию инвестиционных проектов и кластерных инициатив на территории и разрабатывать практические мероприятия по промышленной политике и поддержке отрасли станкостроения, опирающейся на локальные ресурсы, в том числе представленных нематериальными активами (экономико-географическое положение, бренд территории и т.п.).

Предложенные аспекты в традиционной методологии анализа пространственных кластеров в отрасли станкостроения требуют для экономических расчетов как статистических данных, так и оценок нематериальных активов, проведения дополнительного обследования методом анкетирования участников региональных кластеров с целью выявления и оценки кластерных эффектов и межотраслевого взаимодействия на территории региона.

\section{Библиографический список}

1. Портер М. Конкурентное преимущество: Как достичь высокого результата и обеспечить его устойчивость [Электронный ресурс]. Москва. 2008. 714 с.

2. Морозова Е.В. Анализ влияния региональных и федеральных структур на развитие кластерных объединений // Экономика и предпринимательство. 2017. № 9 (ч.2). С. 233-238.

3. Мезенцева О.Е. Управленческие решения: учебное пособие. Тюмень, 2014. 200 с.

4. Гамбаров Г.М. Статистическое моделирование и прогнозирование: [Учеб. пособие для экон. спец. вузов / Г.М. Гамбаров и др.]; Под ред. А.Г. Гранберга. Москва.1990. 382,[1] с.

5. Попадюк Н.К. Процессы субъектизации городов и регионов в региональной экономике как черта переформатирования социально-экономического пространства // Экономика и предпринимательство. 2017. № 9-2 (86). C. 209-214. 